\title{
A CIDADE ESTÁ NA MODA, HÁ POUCO TEMPO: Reflexões gerais
}

\section{Margaret Marchiori Bakos*}

\begin{abstract}
This article examines three aspects not enough studied by historians who work with cities. First, that the city was created in an late period of the history of human kind, comparing to its long period of nomad life. Second, that in spite of the fact that we live in cities for such a short time they are getting old very quickly. And last, that the historian should be in charge of the analyses of these transformations in the cities of this country.
\end{abstract}

É natural que a Revista Estudos Ibero-Americanos tenha escolhido a cidade como eixo temático para um de seus números. Esse é um assunto cuja discussão se impõe. Estamos todos perplexos com os problemas oriundos, desde meados deste século, em cidades do mundo todo e, ao longo de apenas algumas décadas, em grande número de capitais brasileiras.

Nunca se escreveu tanto sobre o meio urbano como na atualidade, pois o assunto é instigante e favorece uma gama de fascinantes abordagens. A mais importante, entre todas, no entanto, raramente é mencionada. Contam-se nos dedos os textos que refletem sobre como são novos os fenômenos da sedentarização e da urbanização para a huma-

Professora no Curso de Pós-Graduação em História da Pontifícia Universidade Católica do Rio Grande do Sul, Porto Alegre, RS, Brasil. 
nidade em relação ao longo período em que ela foi nômade. ${ }^{1}$ Segundo reflexão de John Pfeiffer:

"A mais marcante característica do gênio do homem, como espécie, como o mais adaptável dos animais, tem sido sua capacidade de viver em cidades. Desde a perspectiva de tudo que sabemos sobre a evolução do homem, nada poderia ser menos natural. Por mais de quinze milhōes de anos, desde o período em que membros da família do homem primeiramente apareceram sobre a terra, até tempos relativamente recentes, nossos ancestrais eram criaturas nômades, que viviam em pequenos grupos e em amplos espaços abertos."

Este artigo quer fundamentalmente chamar a atenção para este fato magistral: nós vivemos em cidades há menos de 5.000 anos! Essa é uma pequena conjuntura diante do período em que o homem foi errante e insignificante, em termos de tempo cósmico. Ainda, quer refletir sobre algumas experiências em construir e morar em cidades, a partir da criação das primeiras nesses poucos milênios. Essas apontam para a formação dos problemas de convívio em grupo, os quais podem ser sintetizados em torno do fato do nosso aprisionamento em determinados tipos de espaços e de relacionamentos, sem que possamos desenvolver formas ideais de lidar com eles. Ao contrário, desde

1 Essa reflexão me ocorreu no decorrer de um Seminário de História Antiga, por mim ministrado, na UFRGS, em 1987, a partir da leitura do texto de John Pfeiffer: "How man invented cities". Western Civilization, (vol. I), Connecticut: The Dushkin Group, Ine, 1985. Ele diz textualmente: "The most striking mark of man's genius is as a species, as the most adaptable of animals, has been his ability to live in cities. From the perspective of all we know about human evolution, nothing could be more unnatural. For over fifteen million years, from the period when members of the family of man first appeared on earth until relatively recent times, our ancestors were nomadic, small-group, wide-open-spaces creatures. They lived on the move among other moving animals in isolated little bands of a few families, roaming across wildernesses that extended like oceans to the horizon beyond.

"Considering that heritage, the wonder is not that man has trouble getting along in cities but that he can do it at all - that he can learn to live in the same place year round, enclosed in sharp-cornered and brightly-lit rectangular spaces, among noises, most of which are made by machines, within shouting distances of hundred of other people, most of them strangers. Furthermore, such conditions arose so swiftly, practically overnight on the evolutionary time scale, that he hardly had a chance to get used to them. The transition from a world without cities to our present situation took a mere five or six millenniums." 
então, estamos sempre e cada vez mais rapidamente impactados, perplexos, diante das surpresas, geradoras de apreensão, de que a vivência nas cidades pode e de fato nos proporciona cotidianamente.

Finalmente o artigo quer, ao se utilizar principalmente de notícias de jornais atuais como fonte geradora de questionamentos, evidenciar novas abordagens e o potencial, a atualidade e a historicidade da cidade como objeto de pesquisa.

\section{O passar dos anos: problemas e novas abordagens}

Estamos todos juntos, os terráqueos, diante dos desafios criados pelas novas dificuldades que a ocupação humana do planeta foi gerando. Os diferentes aspectos do chamado "fenômeno urbano", além de "novos" na expressão, se produzem rapidamente e são assustadores, em alguns casos. Independente de sua localização, eles podem tornar-se uma ameaça indireta ou direta para o equilíbrio de regiōes distantes, onde se formaram.

Por exemplo, as monumentais inundações, que ocorreram nas grandes cidades do sul deste país, em São Paulo e Rio de Janeiro, no verão de 1998, foram relacionadas ao fenômeno "el niño", cuja geração não está diretamente relacionada com o que se passa nessas capitais. Essas cidades terminaram, mesmo assim, com as suas rotinas afetadas por ele.

Esse caso ilustra o dinamismo das mudanças, em nossa vivência comunitária. O que se viu naquelas capitais teria sido inimaginável, alguns anos atrás: pessoas sendo tiradas de dentro de ônibus por populares, em caíques, que as levavam para lugares onde dava pé, na avenida. E, de cima de um elevado, essa cena era aplaudida por espectadores.

Nessas circunstâncias, percebemos como nossas cidades são vulneráveis, melhor dizendo, despreparadas para oferecer proteção a seus habitantes nos momentos de exceção. Mais do que nunca estamos conscientes da rede de forças, em constantes e tensionantes movimentos, existente na relação homem/hábitat. E vemos que ela pode ser posta em xeque e até destruída em nossas urbes.

Há outros aspectos ainda quanto à vida em comunidade, que nos impressionam e que são relativamente novos. Se nossos antepassados amargavam em jornadas lentas para ir de um lugar para outro, nós 
precisamos de um novo código de trânsito para viajarmos por estradas, onde o automóvel se tornou, mais do que um meio de transporte, uma arma mortal. Mas, realmente assustadora, é a necessidade de uma fiscalização magistral desse mesmo código de trânsito, até mesmo para atravessarmos as ruas, em frente de nossas casas. Não faz grande efeito uma sinaleira, pois quase na mesma proporção em que há carros transitando, há motoristas mal educados, apressados, e que não respeitam os sinais. Poucas pessoas previram isso ao escolherem, anos atrás, lugar para morar em uma cidade brasileira.

Retornando a Pfeiffer, em um momento de seu texto, ele diz:

"A cidade evoluiu para fazer frente às necessidades das sociedades sob pressão. As pessoas estavam sendo varridas num processo que tinha sido colocado em movimento por suas próprias atividades e que elas jamais poderiam haver predito, pela simples razão de que elas não tinham a visão do que estavam fazendo, em primeiro lugar. (...).",

Pfeiffer termina dizendo que as pessoas não poderiam saber que, ao inventarem a cidade, elas seriam as vítimas de sua criação.

Outra abordagem nova e instigante sobre a urbe é o significado do seu aniversário de fundação. Ao celebrarmos essa data como um ato de renovação, raramente pensamos que isso está marcando mais uma etapa também do seu processo de envelhecimento. Pensamos e agimos nessas cerimônias como se vivêssemos em uma fase da história em que a concepção de tempo era a mítica. Assim, brindamos aquele momento como se fosse de renascimento e mormente de alegria, o qual magicamente promoveria a renovação cíclica do centro urbano

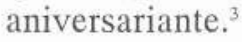

Infelizmente é um ledo engano, pois assusta a conscientização desse fato. É preciso dar um basta a tanto foguetório nessas datas e aproveitar tais ensejos para repensar os efeitos do passar dos anos para a cidade, tanto para as novas como para aquelas nascidas do improviso da ocupação do espaço, e já quatrocentonas.

As reflexốes sobre o tempo e a História tais como às relativas às cidades são muito freqüentes, nos dias atuais. Segundo o raciocínio de Marc Augé, sintetizado por Ciro F. Cardoso: "o tempo, hoje, deixou

\footnotetext{
2 Pfeiffer, op. cit., p. 7

3 Sobre o tempo mítico, ver: Eliade, Mircea $O$ mito do eterno retorno, Lisboa: Gallimard, 1969.
} 
de ser um princípio de inteligibilidade, com a crise da noção de progresso e portanto da história com sentido, evolutiva." 4 Se por um lado, com o teórico, pode-se concordar com Augé, de outro, com o prático, fica difícil, pois na História das cidades o passar dos anos influi muito na qualidade de vida dos seus habitantes.

Teorias à parte, o tempo da humanidade e das suas construções tem, sim, um ritmo linear! A idade de uma cidade apresenta, nessa ótica, os seus lados preocupantes! Somos levados a assim concluir pelas nossas próprias vivências: quando nos racionam a água, porque houve seca ou evidente abuso de reservas; quando tropeçamos nas calçadas, porque elas estão mal conservadas, esburacadas, o que provoca até quedas; quando nos falta luz, porque a rede está sobrecarregada. Principalmente nos flagramos dessa realidade da decrepitude dos serviços urbanos na necessidade das telecomunicações, obviamente incompetentes face às exigências dos novos aparelhos de uso cotidiano da população, como os computadores. Todos que os utilizamos, temos uma triste história a contar sobre a perda de uma idéia/trecho de artigo, relacionada com uma "simples" falta de corrente elétrica.

Além disso, ultimamente, os primeiros sinais perigosos da senilidade das cidades tornaram-se manchetes, até de jornais norteamericanos.

Esse rápido processo de envelhecimento das “jovens" megalópolis do planeta foi mostrado no dia 8 de março passado, na Folha de São Paulo, em um artigo impressionante: "Acidentes mostram que Nova Iorque já sente o peso da idade”. Rick Hansen, do USA Today, daquela cidade, afirmou que a criminalidade não é a única coisa que está em queda na maior cidade dos Estados Unidos. Ali, tijolos, muros e guindastes despencaram das alturas nos últimos meses, deixando os cidadãos nova-iorquinos saudosos dos dias em que só precisavam se preocupar com os assaltantes.

O restante do artigo discrimina fachadas que caíram, prédios que desabaram, tubo de água que inundou a Quinta Avenida, causando o aparecimento de um buraco no asfalto, tăo grande que quase engoliu um carro e provocou um incêndio de gás natural com chamas da altura de um prédio de dois andares. Peritos, segundo o articulista, dizẹm

Marc Augé, apud Cardoso, C. F. "História do Poder, história política". Estudos Ibero-Americanos, PUCRS, v. XXIII, n. 1, 1997, p. 123. 
que os acidentes não são coincidências: “Ao completar seu centésimo ano como cidade unificada e composta de cinco distritos, Nova Iorque começa a sentir a idade pesar".

Além de se deteriorarem com o passar do tempo, as grandes cidades, como as pequenas, estão sempre lidando atualmente com os transtornos das vindas constantes de magotes de pessoas. Esse problema também poderia ser historicamente analisado. Todos vivenciamos em nossas cidades as transformações ligada ao fato de que:

"A terra é vista do espaço como pequena bola colorida: algo distante, insignificante. Ao mesmo tempo, porém, o nosso mundo - tornado pequeno pelas comunicações instantâneas e os transportes rápidos - é superabundante em espaço, posto que todo o espaço do planeta está virtualmente aberto às pessoas."

Os motivos das vindas das pessoas para as cidades, como sabemos, variam e demonstram pouca originalidade, atualmente: ou elas vêm por prazos determinados, para turismo por exemplo e, nesse caso, o fluxo de pessoas é até estimulado, pois traz renda e justifica investimentos na recepção à população flutuante; ou elas são atraídas pelas potencialidades das cidades de absorver mão-de-obra, nem sempre possíveis na prática; ou as pessoas, que estão passando por dificuldades materiais, vêem as cidades como alternativas fantasiosas. Nesses casos, pode ocorrer de elas saírem de onde se sentem carentes para um centro urbano grande, sem avaliar as reais possibilidades de lá serem aceitas. A mudança de domicílio é justificada pela esperança de melhorar a vida. Mas quem pensa assim, além dessas pessoas?

Em alguns casos migratórios, as cidades mostram suas facetas mais hostis, elas não oferecem nem comitês de boas vindas, nem albergues. Se as pessoas chegam com alguma renda, podem ir para as pensões baratas, onde dividem, com outras de diferentes origens, quartos ecumênicos e cozinhas com jeito de "saloon". Se nada possuem, elas, quando obtêm permissão dos moradores "tradicionais", tendem a aumentar o número dos favelados ou dos freqüentadores de dormitórios construídos, toda noite, embaixo de pontes, no interior de estaçôes de metrô. Todos esses arranjos proliferam nas cidades, até

\footnotetext{
Marc Augé, loc. cit., p. 124.
}

6 Esse tema é tāo atual, quanto antigo na história da cidade. É assunto de reportagem em uma revista de divulgação popular, mas raramente das análises histórico-acadêmicas. 
mesmo nas do Primeiro Mundo, como no caso notoriamente conhecido, de São Francisco, na Califórnia. Ali, publica-se um jornal intitulado Lençol da rua. ${ }^{7}$

Recentemente, alguns prefeitos do Rio Grande do Sul tentaram impedir a entrada e o estabelecimento de novas famílias nas circunscrições de seus municípios. Eles justificaram essas medidas autoritárias com o fato de que a administração pública não tem condições, sequer, de oferecer aos habitantes antigos os serviços básicos de primeira necessidade, muito menos aos recém-chegados. ${ }^{8}$ As atitudes dos edis foram duramente criticadas até mesmo pelos seus eleitores.

Será que é por essa via que se solucionarão os problemas urbanos?

As estimativas mais recentes da ONU indicam que mais de 5 bilhổes de pessoas estarão vivendo em cidades em 2025. Transtornados, atualmente, com os problemas diários da vivência urbana, certamente ocorre, a muitos de nós, o mesmo questionamento que acompanha essa informação: "Como será a qualidade de vida nesses centros? Quantos terão um lugar digno para morar? E água tratada e serviços de esgotos pluvial e cloacal?"

Se essas questões afligem até os países ricos, com mais condições de ter um padrão de melhor qualidade de vida, como os pobres lidarão com elas?

Lévy-Strauss afirmou, em uma conhecida passagem de Triste Trópicos, referindo-se mais diretamente a São Paulo, que as cidades do Novo Mundo passaram da barbárie à decadência, do frescor à decrepitude, sem propriamente conhecer a civilização. Esse comentário provavelmente espontâneo do antropólogo, oriundo de sua perspicácia e capacidade de tecer comparações entre as cidades européias e as desse país, está sendo revalorizado pela imprensa brasileira e tido como um alerta para o futuro de nossas cidades. Ele possivelmente irá constranger a alguns historiadores a recuperarem etapas das forma-

\footnotetext{
7 Em inglês: Street Sheet.

8 Segundo Ana Maria Brasileiro, é muito limitado o poder de decisão do governo municipal na busca de soluçōes para os problemas que afligem a cidade, e a possibilidade de atuação no sentido de orientar o seu crescimento segundo os princípios da eqüidade e da eficiência. Decide-se a nível de sociedade global uma série de fatores que têm impacto direto sobre o crescimento e funcionamento da cidade. Apud. Bakos, M. M. Porto Alegre e seus eternos intendentes, Porto Alegre: EDIPUCRS, 1996, p. 24.
} 
ções urbanas brasileiras até agora por eles relegadas a um segundo plano, pelo menos para testar a hipótese subjacente à observação informal do cientista. ${ }^{9}$

Ainda no rol das novas abordagens sobre as metrópoles, é importante incluir a História da defesa de seus valores materiais ou afetivos, seja por iniciativa de grupos, seja individualmente. Essa idéia de um assunto para pesquisa na temática da cidade gerou-se a partir de uma manchete na edição de Zero Hora, de 20 de abril, do corrente: "Cidadão ecológico". ${ }^{10}$ Nela, relata-se um fato passado em Porto Alegre em 1975, quando um estudante subiu em uma árvore - uma centenária paineira - na Avenida João Pessoa, uma das mais importantes no centro desta capital, e ali permaneceu por um dia inteiro.

O objetivo era impedir que a árvore fosse derrubada pelos operários, que construíam uma elevada na área, os quais estavam instruídos a fazer a poda. O gesto do rapaz salvou do corte aquela árvore e, provavelmente, outras, e ele, 23 anos depois, oriundo de Minas Gerais, recebeu, por aquele gesto humano, em sessão solene da Câmara de Vereadores da capital, o título de cidadão de Porto Alegre.

O episódio, além de instigar à reflexão sobre os significados possíveis de um gesto como aquele no processo histórico de uma cidade, ainda induz a pensar sobre o papel dos vereadores e sobre os valores que norteiam as suas decisões. Nesse caso, temos que estabelecer diferentes conjunturas para essa ponderaçāo, desde a dos vereadores que autorizaram o plantio das árvores, a dos parlamentares que as preservaram, a dos vereadores que autorizaram o corte das árvores, terminando na atualidade. Todos esse homens foram eleitos, em princípio para representarem os interesses da população porto-alegrense.

Em geral, as populações urbanas querem basicamente qualidade de vida. Atualmente, a sombra, o papel saudável das áreas verdes como agentes purificadores do ar da cidade e, porque não, a beleza das paineiras, se comparadas a prédios de concreto estão muito valorizados, e não apenas justificariam o gesto do estudante, como comandariam a sua imitação, em massa. E naquela época? Sabemos que Porto Alegre é considerada uma das cidades com maior qualidade de vida no País. Em quais conjunturas de sua história se ponderou sobre

\footnotetext{
$9 \quad$ Folha de São Paulo, 18 de janeiro de 1988.

10 Zero Hora, Porto Alegre, 20 de abril de 1998.
} 
a importância de investir na construção de áreas verdes, o que permite atualmente que ela tenha esse excelente referencial a nível nacional?

Assim, nesse resgate, poderiam aparecer aspectos da incongruência entre os atos dos representantes do povo e os desejos de seus eleitores ou não, bem como entre os seus discursos expressos por atitudes ou verbalmente. Outro ponto para analisar, nessa questão, é que os vereadores da atualidade estão homenageando uma pessoa comum, que foi contra os ditames de uma política urbana, sancionada pela legislação de seus iguais, feita há vinte e três anos. Naquela ocasião, em um primeiro momento, o ato do estudante foi classificado como de desobediência civil. No entanto, hoje ele é premiado.

Entraríamos nessa discussão na História do poder, suas instâncias, seus discursos e representantes, uma faceta da História política muito promissora para o resgate da História das cidades.

\section{A historicidade da cidade}

Como vimos, as primeiras cidades apareceram em uma etapa tardia da História humana. Nós sabemos que, desde os primeiros centros urbanos mais antigos, na Índia, Mohenjo Dara e Harappa, passando por aqueles que se desenvolveram na região da Mesopotâmia, ao longo dos rios Tigre e Eufrates, em cerca de 4.000 a. C., e no Egito Antigo, os homens vão se ajuntando de forma pensada, articulada, e sempre em busca de todos os confortos disponíveis na sua época. Esse planejamento foi paulatinamente deixando o nomadismo menos atraente que a vivência em comunidade. ${ }^{11}$ Entre os maiores problemas que surgiam nas novas situações, segundo Pfeiffer, estava o fato de que o homem foi enjaulado em espaços simétricos, calculados, quadrados e vigiados. ${ }^{12}$

Akhetaton (El Amarna), a capital do faraó herético Amenófis IV, é o primeiro exemplo de uma nova capital construída como instrumento de reforma política-cultural (1475-1358 a. C.). Ainda um modelo perfeito de uma cidade planejada face seus objetivos bem definidos: centro administrativo nacional, pois ali residia o faraó, e cidade-

11 Entre as inúmeras obras publicadas sobre as primeiras cidades salienta-se: Man, settlement and urbanism. London: Duckworth, 1972.

12 Pfeiffer, op. cit., p. 7 
templo do culto ao deus Aton, o que lhe propiciou características peculiares. A nova religião, fundamentalmente crítica ao culto do tradicional deus Amon, era extremamente simples. Adorava o disco solar, representado por um disco de raios que terminam em mãozinhas, mas também podia ser visto no céu e adorado em templos abertos através de hinos e poemas.

Era fundamental a construção de locais especiais para um culto tão diferente, assim como era importante fugir da influência dos sacerdotes do deus Amon, em Tebas. Dessa forma, o local escolhido para a construção do templo consagrado ao culto de Aton, calculado por meios astronômicos, foi decisivo para a determinação da rua principal - a rua do rei, que cortava a cidade de norte a sul, formando a sua espinha dorsal e as áreas residenciais e os prédios administrati$\operatorname{vos}^{13}$

Inúmeros estudos sobre os muito bem conservados vestígios da cidade permitiram pontuar as diferenças sociais entre as pessoas que ali viveram. Eles evidenciaram moradias grandes, com jardins extensos, pátios, depósitos, estábulos cercados por muros que protegiam a privacidade dos residentes aos olhares da massa da população, a qual vivia em casas menores, muitas vezes conjugadas.

Havia seis tipos diferentes de habitações em El Amarna, abrigando uma população de cerca de 30.000 pessoas. Na parte central observa-se um verdadeiro plano regular, especialmente no subúrbio norte; no restante, semelhante às cidades árabes medievais, havia um enredado de ruas estreitas, justaposição de casas habitadas por pessoas de diferentes posições sociais, caracterizando a claustrofilia que é a essência do viver bem sucedido em comunidade.

A importância de refletir sobre essa cidade específica consiste no fato de que ela foi planejada e construída em cinco anos, com objetivos bem definidos. Ela foi habitada por um curto período de cerca de quinze anos e depois, quando da morte de seu mentor, o Faraó, foi completamente abandonada. As areias do deserto cobriram toda a área da cidade, por séculos. Ela foi, assim, conservada pela natureza, e quando foi redescoberta e explorada, em finais do século XIX, isso significou, em termos históricos e arqueológicos, bem mais do que os

13 Bakos, Margaret Marchiori Fatos e mitos do antigo Egito. Porto Alegre: EDIPUCRS, 1995, p. 11-17. 
achados anteriores, os quais foram dispersados e comprados por particulares ou museus. ${ }^{14}$

Entre os inúmeros estudos feitos sobre os remanescentes dessa capital, alguns permitiram saber que os serviços básicos de primeira necessidade foram pensados e eram executados sistematicamente, mediante pagamentos, o que os tornava acessíveis aos mais abonados.

A originalidade da história de El Amarna, ligada ao sonho de poder de um líder nacional, o perfeito desenho de suas vias e prédios, construídos em apenas cinco anos, inúmeras vezes levou cientistas e curiosos a fazer uma comparação entre essa cidade antiga e a capital brasileira. Mas as ilações, nesse sentido, são apenas pitorescas.

A quantidade e a estruturação de centenas de outras cidades construídas ao longo do Nilo, levaram alguns egiptólogos a afirmarem que os arquitetos daquela civilização desenvolveram os planos de ruas e cidades 2.000 anos antes de Hippodamus, com o que enfurecem-se os helenistas, ${ }^{15}$ pois esses atribuem aos gregos, com a sua formação racional de pensamento, a capacidade de idealizar e construir uma cidade planejada.

Outro aspecto do fenômeno urbano no Egito foi o da cidadefortaleza. O planejamento desses sítios de habitação foi tão cuidadoso que os egípcios podem ser considerados os precursores de Vauban, o gênio da arquitetura militar do século XVI. Certamente, essa referência à antigüidade remota de um tipo de agrupamento de defesa também não é bem aceita por aqueles que desconhecem a História da Arquitetura e tudo que foi feito nessa arte, desde as primeiras etapas de sedentarização da humanidade.

Se seguirmos cronologicamente a tradicional divisão da História do gênero humano, do surgimento da escrita, ao período medieval e aos tempos modernos, poderemos resgatar, em regiões diferentes, através das constantes transformações dos núcleos urbanos, os problemas crônicos e os inusitados.

Como vimos, as cidades foram criadas em época recente da História da humanidade. Ainda que elas tenham se constituído em criações de controle humano sobre o meio ambiente, esse controle era pequeno

14 Essa discussão é feita em muitos livros, salienta-se o de G. Sée: Naissance de l'urbanism dans le valée du Nil. Paris: Ed. Serg, 1973.

15 Ver a síntese de E. Uphill: Egyptian town and cities. London. Shire Publication Ltd, 1988. 
e frágil. Somente a partir da Idade Média se produziu um ciclo de criação urbana que continua na atualidade. Este ciclo, que está durando há mais de mil anos e que semeou pelo planeta a fundação de milhares de cidades com dimensões enormes, parece hoje infindável. ${ }^{16}$ Será que podemos incentivar esta expectativa?

Inicialmente, é preciso valorizar as informaçōes acumuladas de experiências de enfrentamento corpo a corpo de pessoas, na disputa pelos espaços privilegiados, seja para a construção de cidades, seja para a moradia nelas. Naqueles processos, aconteceu muitas vezes, como é o caso das cidades do sul da Itália, do período medieval, que as pessoas se agruparam muito, a ponto de um vizinho, do outro lado da rua, ouvir até mesmo os menores ruídos feitos pelos habitantes do prédio fronteiriço e sentir todos os odores deles!

Há algo em comum, nessa descrição, com o que se passa na convivência entre as pessoas, em condomínios de casas principalmente. Construídas de forma geminada, elas permitem que se ouçam os mínimos barulhos. A estreita ruela do "rei" que separa as moradias, em lado leste e oeste, geralmente, permite, graças à moderna tecnologia, que os sons feitos em cada uma delas se projetem a ponto de perturbar a paz de todas. O mesmo acontece com os cheiros, por ser possível saber, até mesmo, o que o vizinho vai comer no jantar.

Voltando a Pfeiffer, ele considera que a maior característica do gênio do homem, como espécie, como o mais adaptável dos animais, tem sido a sua capacidade de viver em cidades:

“(...) não é de se admirar que o Homem tenha problemas em dar-se bem em cidades, mas sim que ele possa fazê-lo, afinal, que ele possa apreender a viver no mesmo lugar o ano todo, fechado em espaços retangulares brilhantemente iluminados e com ângulos agudos, entre ruídos - a maioria dos quais feitos por máquinas - e a uma distância de ouvir gritos de centenas de outras pessoas, em sua maioria estranhos. Mais ainda, tais condições desenvolveram-se tão rapidamente, praticamente do dia para a noite na escala de tempo, que ele dificilmente teve oportunidade de acostumar-se com elas." 17

Assim, do mesmo modo como é pouco comum notar o recente fenômeno da sedentarização, igualmente pouco se enfatiza a historici-

16 Galentay, E. Nuevas cidades. Barcelona: G. Gili, 1978, p. 14.

17 Pfeiffer, op. cit., p. 7. 
dade das vivências urbanas. A cidade sempre se configurou como um grande palco, onde as performances humanas mais brilhantes foram basicamente as de caráter público. Os políticos foram sempre os seus artistas principais, enquanto o grande número de citadinos mantiveram-se no anonimato. Sem dúvida, a maioria dos atores urbanos, fossem astros ou figurantes, procuraram preservar inicialmente a intimidade do seu clã, e, depois, da família nuclear. Isso aparece nas tentativas de zoneamento das cidades, que, como vimos, são feitas já nas primeiras fases do processo de urbanização.

Pelas preocupações profissionais, coube basicamente aos arquitetos a primazia, entre os cientistas sociais, de escreverem sobre a História das cidades. Foi da autoria de um arquiteto dinamarquês Steen Einer Rassmussen -, por exemplo, em 1848, o primeiro livro "clássico" sobre Londres: London: The Unique City, ${ }^{18}$ uma obra didática sobre a metrópole, que por mais de três séculos foi a maior cidade do ocidente.

A formação técnica dos arquitetos levou-os a sistematizar e a ligar aspectos diversos e importantes para o estudo de um agrupamento humano organizado. Eles geralmente iniciam suas análises quando buscam saber por que o lugar foi o escolhido para a instalação de um núcleo de vivência. Elencam as vantagens geofísicas do local e as relacionam com os propósitos conjunturais dos homens.

Nessa análise, os arquitetos se preocupam, via de regra, com as origens étnicas e as respectivas visões de mundo dos habitantes. Muitos desses historiadores "improvisados" tornaram-se renomados escribas das cidades, onde exerceram seus ofícios.

Mas, certamente, foram os sociólogos, preocupados com as vivências nas cidades, que deram o grande avanço em termos teóricos sobre a História das cidades. Apenas para exemplificar, pois a bibliografia é grande, Peter Saunders, contemporâneo, publicou em 1981 um compêndio de cunho didático sobre a teoria social e a questão urbana. ${ }^{19}$ Ele discorreu, no livro, sobre as referências feitas nas obras de Marx e de Engels em torno da cidade, do país e do modo capitalista de produção; sobre Max Weber, a cidade e o crescimento da

18 Rassmussen, S. E. London: the unique city. London: 1848.

19 Saunders, Peter. Social Theory and the Urban Question. London: Billing \& Sons, 1981. 
racionalidade e sobre Émile Durkheim, a divisão do trabalho e as bases morais da comunidade.

Saunders discutiu, no segundo capítulo, o urbano como uma comunidade ecológica, no terceiro, o urbano como uma forma cultural, no quarto, o urbano como um sistema sócio-espacial e, no último, finalmente, o urbano como ideologia.

Já em 1967, Guy Debord publicou o livro Sociedade do espetáculo, ${ }^{20}$ o qual, apesar de reeditado em 1971, só recentemente teve suas idéias adequadamente valorizadas. Naquela obra ele divulgava seu pensamento sobre a cidade como "espaço da história", porque é ao mesmo tempo concentração do poder social, que torna possível a empreitada histórica e a consciência do passado.

É difícil pensar a cidade isoladamente, destacar, engessar uma parte dela, para um estudo puramente monográfico, após ler e refletir sobre quantas propostas foram feitas no sentido de mostrar a complexidade que envolve o estudo de um núcleo urbano, por menor que seja. Certamente, quando pensamos na cidade em relação regional e com o país, e quando buscamos sistematizar diferenças, para melhor entendê-la em sua singularidade, estamos fazendo um trabalho de cunho histórico. É um trabalho de valor inestimável, inclusive se considerarmos os aspectos apenas presentes no aqui e no agora das nossas análises extraídas de nossa memória e vivência pessoais. Nessa ótica, as questões urbanas tornam-se mais vivas, pois nos sentimos, ao mesmo tempo, causadores e vítimas de muitas de suas facetas.

Nada mais natural que alguém refletir sobre a cidade onde nasceu ou em que viveu por tempo significativo. Não é possível para os historiadores deixar fluir as idéias para o papel como fez Campos de Carvalho: "fui morar sob a ponte do Sena, embora nunca tenha estado em Paris", ${ }^{21}$ sobre um personagem fictício. Essa criatividade é permitida aos romancistas, não a um historiador. Esse profissional deve ressuscitar os mortos, com muito respeito, não lhes atribuindo qualidades, desejos, nem feitos que sequer sonharam realizar. ${ }^{22}$

\footnotetext{
20 Debord, Guy. Sociedade do espetáculo, Rio de Janeiro, 1997.

21 "O fim do surrealista do romance". Zero Hora, 18 de abril de 1998. Segundo Caderno, p. 2

22 Heller, Agnes. Uma teoria da História. Rio de Janeiro: Zahar, 1981. p. 55 e ss.
} 


\section{Reflexões na "sala de visitas"}

Na escolha de um tema e de seu recorte é importante que o Historiador avalie o que lhe é caro e instigante. Assuntos e abordagens da moda no exterior e mesmo no País nem sempre preenchem tais requisitos. Meu interesse pela temática urbana tem a ver com a minha vivência em Porto Alegre - carinhosamente denominada em alguns textos do século passado como "A sala de visitas do Rio Grande do Sul" Esta cidade vem sofrendo, como outras tantas capitais brasileiras, um processo de crescimento desordenado, vem sendo desfigurada pela abertura anárquica de ruas, pelas clandestinas construções de subabitações miseráveis, pelos serviços de utilidade pública insuficientes, muitos de tecnologia obsoleta.

Por considerar esse descaso insuportável, passei a questionar sobre suas origens.

Em 1982, para tema de Tese de Doutorado, decidi estudar um período da história da cidade situado entre os anos de 1897-1937, pois ali se desenvolvera uma qucstão que, pela atualidade, se impunha discutir: a busca pela continuidade de representantes de um partido político - o Republicano Rio-grandense (PRR) - no governo da cidade. Cismei, à época, que entender esse fato me ajudaria na compreensão das relações entre o poder e a construção do espaço de uma cidade, assim, sobre a qualidade vida de Porto Alegre..$^{23}$

Entre os resultados da pesquisa, ficou o entendimento de que o sucesso da permanência do PRR foi tão marcante, que o continuísmo deixou de ser, naquelas circunstâncias, o emprego de bem sucedida estratégia política, para ser parte constitutiva de um fenômeno suigeneris na história do país. Certifiquei-me ainda da importância dos estudos de ordem política para o resgate da história de um centro urbano, pois eles nos configuram os homens, suas ideologias, seus espaços de atuação e o modo e os interesses, envolvidos na sua ocupação. São informações fundamentais para o entendimento da História da cidade.

Sabia, ao iniciar a pesquisa, que análises de cunho político estavam para muitos fora de moda no Brasil, mas, face ao entendimento

23 Desmembrei a tese em inúmeros artigos, já publicados, em diferentes veículos de informação. Na íntegra, o texto se encontra no livro Porto Alegre e seus eternos intendentes, Porto Alegre: Edipucrs, 1996. 
de que as relações político-econômicas, as ideológicas e as vivências sociais interagem, perseverei. E apelei para novos campos de pesquisa histórica, fontes primárias pouca valorizadas até então, tais como relatórios dos Intendentes Municipais e os das repartições públicas contemporâneas.

Descobri que analisar a conduta daqueles chefes políticos implicava entender suas escolhas, por exemplo, entre os diferentes sistemas de fornecimento de energia elétrica, de água e de esgotos e as razões em pauta para alterá-los. Essas, inclusive, tinham que ser compreendidas, sob um ponto de vista técnico, para situar o papel daqueles homens ao decidirem as prioridades de suas gestões.

Precisei lidar com os custos e os cálculos feitos à época para estipular, realizar e valorizar o significado da cobrança de impostos, para a administração pública, especialmente o predial, que se revelou um dos mais significativos.

Para arriscar os efeitos possíveis, em termos de endividamento a longo prazo, das cláusulas dos empréstimos contraídos para a realização de todas as empreitadas planejadas, levadas a efeito por aqueles governantes, foi necessário rever inúmeras vezes fontes diversas e sistematizar as informações minuciosamente.

Enfim, como em toda a investigação, foi preciso, para essa, achar um fio condutor. No início, "flutuava como uma rolha sobre o mar de minhas pesquisas", segundo palavras de Phillipe Ariès. ${ }^{24}$

Ainda parodiando esse autor, quanto à sua avaliação sobre o estágio de estudo acerca da temática da morte, quando ele iniciou suas pesquisas sobre esse tema, posso afirmar que era muito pobre a historiografia sobre Porto Alegre, nos anos oitenta, e que " havia tanto a ser feito $[\ldots]^{\prime \prime} \cdot{ }^{25}$

O que tinha sido escrito sobre "A sala de visitas" até então? O pequeno número de textos específicos disponíveis, à época, sobre Porto Alegre foi, posteriormente, acrescido de vários outros, divulgado em uma publicação de consulta indispensável para todos que desejarem conhecer a historiografia sobre a cidade disponível: $O$ que ler para conhecer Porto Alegre. ${ }^{26}$

24 Ariès, P. Um historiador diletante. Rio de Janeiro: Bertrand Brasil, 1994, p. 164.

25 Ariès, op. cit. p. 164.

26 O livro intitula-se: O que ler para conhecer Porto Alegre, Porto Alegre: Ed. da Universidade, 1991. Trata-se de um minucioso levantamento de indicações biblio- 
Algumas leituras foram fundamentais para a minha pesquisa, seja pela originalidade de suas idéias, muitas das quais incorporei a minha visão de mundo, seja pelas informações de cunho empírico, que me pouparam recorrer a fontes primárias.

Dos historiadores, entre outros, saliento os trabalhos de Sérgio da Costa Franco ${ }^{27}$ e o de Laudelino Medeiros, Vila de malocas ${ }^{28}$, surpreendente, à época. Como ponto de partida para as leituras de cunho teórico, das quais me ressentia na minha formação acadêmica em História, o texto de Rubem Oliven: "A cidade como categoria sociológica”. ${ }^{29}$ Fiquei encantada com a série de estudos organizada por Eva Alterman Blay ${ }^{30}$ sobre a luta pelo espaço e de Ana Maria Brasileiro ${ }^{31}$ sobre os serviços básicos para áreas urbanas.

O livro de Carlos Lemos, Casas, cozinhas, etc., ${ }^{32}$ foi básico para meu trabalho, não como fonte de dados, mas como provocador de idéias. $\mathrm{O}$ autor, um arquiteto, me levou a admirar o potencial desses especialistas para lidarem com a História de uma cidade.

Ao sistematizar fatos históricos das urbes, sem pretensōes de escreverem obras monumentais, mas sim, de entenderem a ocupação do espaço ao longo do processo de crescimento de Porto Alegre, os arquitetos foram pontuais na determinação dos seus recortes temporais. As buscas de origem serviram, apenas, como viés provocativo de uma reflexão mais objetiva em torno de problemáticas recentes da cidade.

gráficas comentadas, indispensável para quem for iniciar alguma pesquisa sobre a História da cidade.

27 Costa Franco, S. Porto Alegre e seu comércio. Porto Alegre: Associação Comercial de Porto Alegre, 1983.

28 Medeiros, Laudelino. Vila de Malocas, Porto Alegre: Multilite, 1951.

29 Esse texto foi publicado na Revista Dados, Rio de Janeiro, 19, 1978. Ele foi tão importante para orientar a minha, então, confusa visão do que é uma cidade, que venho, desde a tomada de conhecimento dele, sistematicamente, oferecendo sua leitura para meus estudantes de História, de diferentes níveis. A resposta a essa indicação tem sido sempre muito positiva. Invariavelmente, os alunos dizem que ela Ihes abriu o caminho, depois dela partem para os grandes compêndios teóricos e fazem suas escolhas metodológicas, mais conscientes da relaçâo delas com suas visôes de mundo.

30 Blay, Eva A. (org.) A luta pelo espaço. Petrópolis: Vozes, 1979.

31 Brasileiro, A. M. "Serviços básicos para áreas urbanas". Fundação Centro de Formaçāo do Servidor Público, Rio de Janeiro, ano 40, v. 3; jan/mar, 1983.

32 O livro de Carlos Lemos, me foi sugerido, no exame de qualificaçāo na USP, por Edgar Carone. 
Por não estarem teleguiados por linhas teóricas estritas, eles valorizaram em suas sínteses as fontes empíricas. Talvez, orientados pela sensibilidade humana, não monitorizada, eles foram capazes de captar os tortuosos caminhos pelos quais a história local fluiu. Eles foram, sem dúvida, os pioneiros em destacar o papel dos líderes políticos indicados para discutir os rumos da cidade, da população, e aliás, também souberam identificar como jamais tendo sido tão silenciosa, quanto a historiografia tradicional costuma arbitrar que ela foi. Haja visto o caso do estudante e da paineira, que referimos anteriormente, apenas para apontar um exemplo de manifestação independente.

Na reduzida historiografia sobre Porto Alegre, da década de oitenta, encontrei inúmeros trabalhos importantes escritos por arquitetos. Sem dúvida o lugar de destaque cabe a Francisco Riopardense de Macedo, com suas inúmeras pesquisas. ${ }^{33}$ Maria Luíza Forneck ${ }^{34}$ produziu excelente análise sobre a segregação residencial em Porto Alegre e Célia de Souza Ferraz ${ }^{35}$ sobre a cidade e sua evolução. Destaco ainda a pesquisa da socióloga Luíza $H$. Pereira, ${ }^{36}$ sobre a habitação popular no Rio Grande do Sul, com capítulo específico sobre a capital do Estado. Essas leituras me mostraram novos viéses a serem analisados sobre Porto Alegre.

Uma menção especial deve ser feita aos artigos de Moema Debiagi sobre a cidade, principalmente "O desenvolvimento habitacional em Porto Alegre e sua relação com o Rio Guaíba", ${ }^{37}$ publicado em 84. Ao valorizar aquela ligação, o escrito tem atualidade, pois vivemos, em Porto Alegre, um momento de euforia. Os administradores finalmente parece terem percebido a cumplicidade que há entre a cidade e suas águas, lindas, que compõem, não importa o nome, lago, estuário

${ }^{33}$ Os livros publicados por Riopardense de Macedo sobre Porto Alegre são numerosos. Recentemente ele fez uma síntese de todos, que foi publicada pela editora da UFRGS, em uma coleção especial para a História do Rio Grande do Sul.

34 Forneck, M. L. A forma da cidade e a segregação residencial. Estudo de caso: a cidade de Porto Alegre. Porto Alegre: UFRGS, 1980. Dissertação de Mestrado, Faculdade de Arquitetura (mimeo).

35 Souza, C. R. et al. Porto Alegre, análise de sua evolução. UFRGS, 1978 (mimeo).

36 Pereira, L. H. Habitação popular no Rio Grande do Sul: 1890-1980. Porto Alegre: UFRGS, 1980. Dissertação de Mestrado em Antropologia, Ciência Política e Sociologia (mimeo).

37 Debiagi, M. O desenvolvimento habitacional de Porto Alegre e sua relação com o rio Guaiba. Porto Alegre: PROPUR, 1984. 
ou rio Guaíba. Vamos provavelmente assistir à derrubada do Muro da Avenida Mauá, o qual, como o de Berlim, desuniu dois universos inseparáveis e a construção de um complexo de lazer naquele local.

Tanto Porto Alegre como o Guaíba foram, ambos, utilizados por pessoas, cujos planos foram feitos, sem dúvida, no sentido de manter os contatos e as visões de um sobre o outro. A cidade surgiu voltada para o Guaíba, que era, entáo, meio de transporte vital para nossa economia e fonte de lazer saudável.

Podemos até levantar a hipótese de que, os outros tantos interesses considerados atualmente na decisão de derrubar o muro são menos importantes para a população, como um todo, do que o privilégio de novamente usufruir do inigualável pôr-do-sol no Guaíba, naquela área para a qual os magníficos prédios portuários servirão de abrigo.

Quem idealizou a construção do muro, aqueles que a apoiaram, os que perceberam as incongruências da iniciativa, mas não se manifestaram contrários a ela, como o mineiro, quando da perspectiva de derrubada da árvore, na av. João Pessoa, certamente ou não conheciam a história da cidade ou, lamentavelmente, não valorizaram a sua própria historicidade, se porto-alegrenses!

Se, ao longo dos anos oitenta, o estudo sobre Porto Alegre foi restrito, ao longo da década de 90 , ele virou moda. Os jovens pesquisadores locais, especialmente os ligados aos cursos de Pós-Graduação, voltaram seus olhos para o estudo desta capital.

Belos trabalhos, merecedores de aplauso, foram feitos por essa safra de historiadores, embora alguns apenas instiguem, no mínimo, uma crítica construtiva sobre a tendência, que abraçaram de desconsiderar o todo, para privilegiar o inusitado. Essa disposição, recorrente em estudos históricos sobre outras temáticas do Rio Grande do Sul, afigura-se, pelo exposto acima, como merecedora de questionamento e de um repensar.

Para reforçar a necessidade dessa pausa para meditação, recorro à pioneira posição assumida, há dez anos, por Joan Scott com relação às pesquisas sobre gênero, quando ela advogou que era preciso parar de se pensar a mulher isolada em um universo, quando, na realidade, o homem também fazia parte dele.

Na história da cidade, a tendência de segmentar o objeto, ao ponto de perder a sua dimensão histórica, está também presente. Ela vem sendo inculcada nos historiadores, pelas pressôes e estímulos, para a adoção de pressupostos e métodos de outras disciplinas para as pes- 
quisas. Muitas vezes esses novos pesquisadores fazem tais opções por ingenuidade, pois é moda, outras, por identificação e desejo de trabalhar consoante às maneiras sugeridas. Outra possibilidade ainda é de que eles não sejam suficientemente informados sobre os princípios básicos que configuram o fazer histórico. Nessas circunstâncias, os jovens historiadores podem até se sentir "culpados" por buscarem compreender ou explicar algum fenômeno.

As perspectivas e as metodologias desenvolvidas pela análise de cunho histórico devem ser revalorizadas. E isto, certamente, não implica abandonar a saudável prática de fazer pesquisas de cunho interdisciplinar. Importante, por exemplo, para estimular a discussão sobre a utilização pelos historiadores dessas abordagens múltiplas e muito ricas com relação às temáticas do urbano, é a posição abalizada e específica de Eunice Ribeiro Durham sobre a antropologia das cidades, conforme está sendo feita neste país, citada por Canclini, a seguir:

“(...) praticou-se menos (...) uma antropologia da cidade do que uma antropologia na cidade. (...) trata-se de pesquisas que operam com temas, conceitos e métodos da antropologia, mas voltados para o estudo de populaçôes que vivem nas cidades. A cidade é, portanto, antes o lugar da investigação do que seu objeto." ${ }^{38}$

Se esse enfoque é criticado até para trabalhos antropológicos propriamente ditos, certamente está ainda mais longe de ser o ideal nas pesquisas dos historiadores das cidades brasileiras.

Se queremos pensar a "cidade", é importante refletirmos sobre a nossa ignorância diante das novas facetas das "questões urbanas" e sobre a nossa perplexidade frente à complexidade e ao grau avassalador dos desafios que ela vem trazendo consigo. Para tal, o historiador avança se buscar conhecer, sistematizar fatos do processo histórico sobre o qual ele se dispõe a pesquisar, recortá-lo e contextualizá-lo, evidentemente, a partir do clareamento das propostas de análise sobre as quais quer refletir, pois elas são inúmeras.

Dicionários de sinônimos e antônimos, obras de intelectuais internacionais consagrados, e enciclopédias estrangeiras costumam ser os preciosos auxiliares para o cultivo de um artesanato de dizer as

38 Duhram E. R., apud Canclini, N. C. Culturas híbridas, São Paulo: Edusp, 1997, p. 249. 
mesmas coisas, de diferentes maneiras, sobre locais diferenciados, de forma muito orgulhosa, publicamente assumida e exibida, às vezes, pelo ostensivo manuseio de volumosos compêndios, diante de uma assistência: se jovem, às vezes ingenuamente encantada, se mais adulta, enfastiada pelo desperdício de tempo e pela demonstração de uma erudição desprezível, se o objetivo é contactar uma cidade específica. ${ }^{39}$ Cabe um questionamento: quais os méritos de exercícios dessa categoria, senão de cunho fundamentalmente literário? Nesse sentido, apenas, eles são certamente muito importantes!

Escrever generalidades sobre ângulos seletivos apenas, de cidades, evitar a questão crucial de que sequer podemos, por desconhecimento, discutir as variáveis da problemática de nossa vivência em megalópolis, sendo essa uma tarefa que se impóe ao historiador, pode deliciar o ego do beletrista, de seus seguidores e dos seus amigos, mas dificilmente irá valorizar o ofício daquele profissional e seu papel social de conscientizador.

O historiador por ofício possui - ou deveria possuir - os instrumentos necessários para pensar na relação sempre existente entre uma cidade e a sua história. Ele poderia, como o rapaz da paineira, dar o alerta, quando uma medida de cunho administrativo tem potencial para, se incrementada, agredir e até mesmo destruir uma relação vital entre o homem e o seu hábitat. $\mathrm{O}$ caso referido acima da construção do muro da Mauá, sem dúvida constituiu um verdadeiro atentado à

39 Pela sua representatividade, no meio acadêmico, como um dos mais populares veículo de informação, impōe-se nesse artigo reproduzir uma nota da Folha de Sāo Paulo, de 21/3/98: "Lévi-Strauss mencionou a formaçāo dos universitários brasileiros voltados para os estudos humanísticos como atualizada nas últimas novidades, mas ignorante dos fundamentos mais sólidos. Com as exceções de regra, isto permanece verdadeiro ainda. Talvez mesmo de maneira acentuada o poder das modas intelectuais continue arrasador. O campo intelectual, que é diverso do da cultura e, com freqüência, distante dela, sabe dissimular sua esterilidade e sua ingenuidade. Os exercícios mentais sobre uma questão, substituem, muitas vezes, o contato longo, sólido e desinteressado com os objetos da cultura, contato que engendra a compreensão densa e fecunda. Poucos livros acabam explicando tudo e assim o pensamento torna-se mecânico, estreito.

"Lê-se ou cita-se mais a torto que a direito, Foucalt, Walter Benjamim, Deleuze, Derrida, Adorno e, agora, Chartier. Esses autores e alguns outros, muito involuntariamente e sem que estejam em causa suas qualidades intrínsecas, terminam sacralizados num âmbito provinciano, oferecendo a ilusão de solucionar todas as lacunas e fragilidades." 
historicidade dos porto-alegrenses e a sua relação básica com as águas. Embora errônea, essa medida pretensamente protetora da cidade, por evitar enchentes, felizmente pode ser sanada, para benefício de todos. Mas nem todas as agressões aos valores historicamente importantes de uma população, sancionados pelos seus vereadores, podem ser revertidos. É importante, e melhor, prevenir que eles aconteçam!

É importante lembrarmos as palavras de Lucien Febvre, selecionadas com maestria por Carlos Guilherme Motta, no prefácio de seu livro sobre o grande mestre:

"Historiadores, sede geógrafos. Sede juristas também, e sociólogos e psicólogos; nâo fecheis os olhos ao movimento que, perante vós, transforma num ritmo vertiginoso as ciências do universo físico. Mas vivei também uma vida prática. Não vos contenteis $\mathrm{em}$ contemplar da orla, preguiçosamente, o que se passa no mar em fúria. No barco ameaçado não sejais como Panurgo se sujando de puro medo, nem mesmo como o bom Pantagruel, contentando-se amarrado ao grande mastro, em implorar, levantando os olhos ao céu. Arregaçai as mangas, como Frei João. E ajudai os marinheiros na faina." ${ }^{40}$

No Brasil, como acontece em vários centros culturais do mundo, elegeu-se a história da cidade como um tema ideal para a pesquisa histórica. De fato, ela pode ser fascinante, especialmente quando estudamos as cidades que nos reportam às suas ruas, onde caminhamos, aos prédios onde moramos e, em especial, àqueles lugares onde fizemos nossas formações pessoais. Aí lembramos os velhos amigos, alguns ainda presentes em nossas vidas, outros que já se foram para outra cidade ou, quiçá, para o "outro mundo".

Ao historiador cabe, nos seus resgates, fazer algo mais: articular e somar raciocínios! Arrisco uma "receita", em se tratando da história das cidades, ainda tão recente, neste país: ele deve colocar na narrativa uma "generosa medida" de ética, ou seja, acrescentar ao seu enfoque, em que ele contribui para a história local e em que soma no que já se escreveu sobre ela. E ainda, uma "boa dose" de interesse humanitário. O que significa: juntar os dados, sistematizados, como se fossem ingredientes, para tornar mais "saborosa", ou seja: mais compreensível, a realidade em que vivemos e, não apenas, o texto.

40 Lucien Febvre, apud Mota, C. G. (org.). Febvre. São Paulo: Ática, 1978. p. 7. 
O recomendável para o exercício profissional de um historiador é exatamente buscar e valorizar as fontes, bem como estar em contato com a comunidade, para atualizar os enfoques. Ou ele será, em pou$\cos$ anos, como algumas peças de museu, as quais embora muito belas esteticamente, por vezes alocam-se tão distantes dos interesses de todos, que são, por fim, esquecidas. E assim a história das cidades continuará a ser feita por outros cientistas sociais, com muito sucesso, diga-se de passagem.

Finalmente, à guisa de conclusão, é importante relembrarmos que a história da cidade é muito curta em relação ao tempo em que a humanidade viveu a esmo. As metrópoles, principalmente, são um fenômeno muito novo. Entretanto, o ritmo de mudanças sofridas no meio urbano vem assumindo ao longo de poucos décadas um ritmo vertiginoso, assustador. Ignorar essas constatações é partir de um enfoque que despreza o tempo, o espaço e as pessoas, que os criaram. Não se trata aqui de valorizar um procedimento de cunho historicista como forma de conhecimento, mas de alertar para o fato de que estudos sobre uma cidade específica, que desvalorizam sua História e desprezam as especificidades do contexto geográfico, onde ela se insere, certamente irão proporcionar textos com abordagens falaciosas e historiograficamente falhas ou irrelevantes."

* Agradeço a disponibilidade da colega Ruth Gauer de ler este artigo e discutir comigo seus aspectos mais importantes. 